\title{
Realistic Creativity Training for Innovation Practitioners: The Know-Recognize-React Model
}

\author{
Dagny Valgeirsdottir and Balder Onarheim
}

\author{
"Know where to find the information and how") \\ to use it. That is the key to success.
}

Albert Einstein (1879-1955)

Theoretical physicist and Nobel laureate (1921)

\begin{abstract}
Creativity is increasingly being recognized as important raw material for innovation, which highlights the importance of identifying ways to increase the creativity of practitioners. In this article, we describe our efforts to design a creativity training program specifically for innovation practitioners. Our aim was to develop a program that would be both theoretically sound (i.e., based on a rigorous scientific foundation) and relevant for practitioners (i.e., applicable to real-world contexts). Our transdisciplinary study employed co-creation as a method to ensure that three layers of focus would be taken into consideration: metacognitive knowledge, metacognitive monitoring, and metacognitive control. The result is a program called Creative Awareness Training, which is based on the new Know-Recognize-React model.
\end{abstract}

\section{Introduction}

It is widely accepted in academic circles that creative thinking is an important element in innovation (e.g., Amabile, 1996; Christiaans, 1992; Dorst \& Cross, 2001). Creativity is moreover believed to be the necessary precondition for innovation; one may argue that without the presence of a creative act, idea, or output, no innovation will happen. Indeed, Amabile and colleagues (1996) state that "All innovation begins with creative ideas". This is the root of our interest in enhancing creativity, which we see as the raw material of innovation: the individual creativity of innovators.

Creativity is a basic human skill, which can indeed be transformed gradually through long-term education, however, numerous studies have demonstrated that this skill can also be improved through shorter interventions such as dedicated training programs (see e.g., Scott et al., 2004). Many different approaches to creativity training have been established, although most current creativity training programs are directed at enhancing individual creativity skills on a cognitive level (Scott et al., 2004). Despite a multitude of training approaches in the current landscape, there seems to be a lack of rigorously developed and tested creativity training programs (Valgeirsdottir \& Onarheim, in press) designed specifically for practitioners in the fuzzy front end of innovation, as defined by Koen and colleagues (2002), hereafter termed innovators.

To address this gap, we undertook a series of studies, the fourth of which is described in the present article (Figure 1). We first set out to investigate how creativity skills influence the creative process of innovators with the purpose of determining what is important to them when using creative thinking abilities. Through an initial research effort - Study A (Valgeirsdottir et al., 2016) - we found that, when individuals showed awareness of the creative process flow and the underlying cognitive processes accompanying it, and used this awareness to facilitate their own and their team members processes, it appeared to benefit the collective creative process. Following Study A and a related literature review (Study B: Valgeirsdottir \& Onarheim, in press), we wanted to elaborate on and investigate this finding through observational research (Study C: Valgeirsdottir \& Onarheim 2016). Resulting from that work, we developed a definition of a metacognitive creativity skill we termed "creative awareness", which will be described in more detail 


\section{Realistic Creativity Training for Innovation Practitioners: Know-Recognize-React}

Dagny Valgeirsdottir and Balder Onarheim

below. The current study builds on these three previous research efforts by developing a training program that would enable creative awareness of creativity-related processes. By adapting methods from transdisciplinary strategizing (e.g., Rasmussen et al., 2010) and co-creation (Sanders \& Stappers, 2008), we developed a creativity training program specifically designed for innovators. The overall research process can be seen in Figure 1 below, with the current study and its five interventions (IVs) being delimited to the "co-creation" section of the figure.

The overall research question we defined for our study was: Which creativity concepts and cognitive processes are important to emphasize in training to enable creative awareness? This question was addressed at three different levels of stakeholders (see Figure 1) in a creativity training context:

1. Relevant: involving representatives of innovators to ensure a relevant training program
2. Theoretically sound: involving creativity academics to establish a program that is theoretically sound

3. Realistic: involving company representatives responsible for employee development (i.e., HR managers) to provide the perspective of what is realistic in a realworld context

The preliminary program design, resulting from the first three interventions, was then introduced to educational researchers for validation through two additional interventions to ensure a robust design (Rasmussen et al., 2010). The purpose of this article is to describe our transdisciplinary study and the co-creation process we designed to investigate these aspects, as well as the resulting conceptualization of our creativity training program: "Creative Awareness Training".

The article is structured as follows. First, we provide a theoretical background, framing the key concepts in a broader perspective. Next, we describe the methodolo-

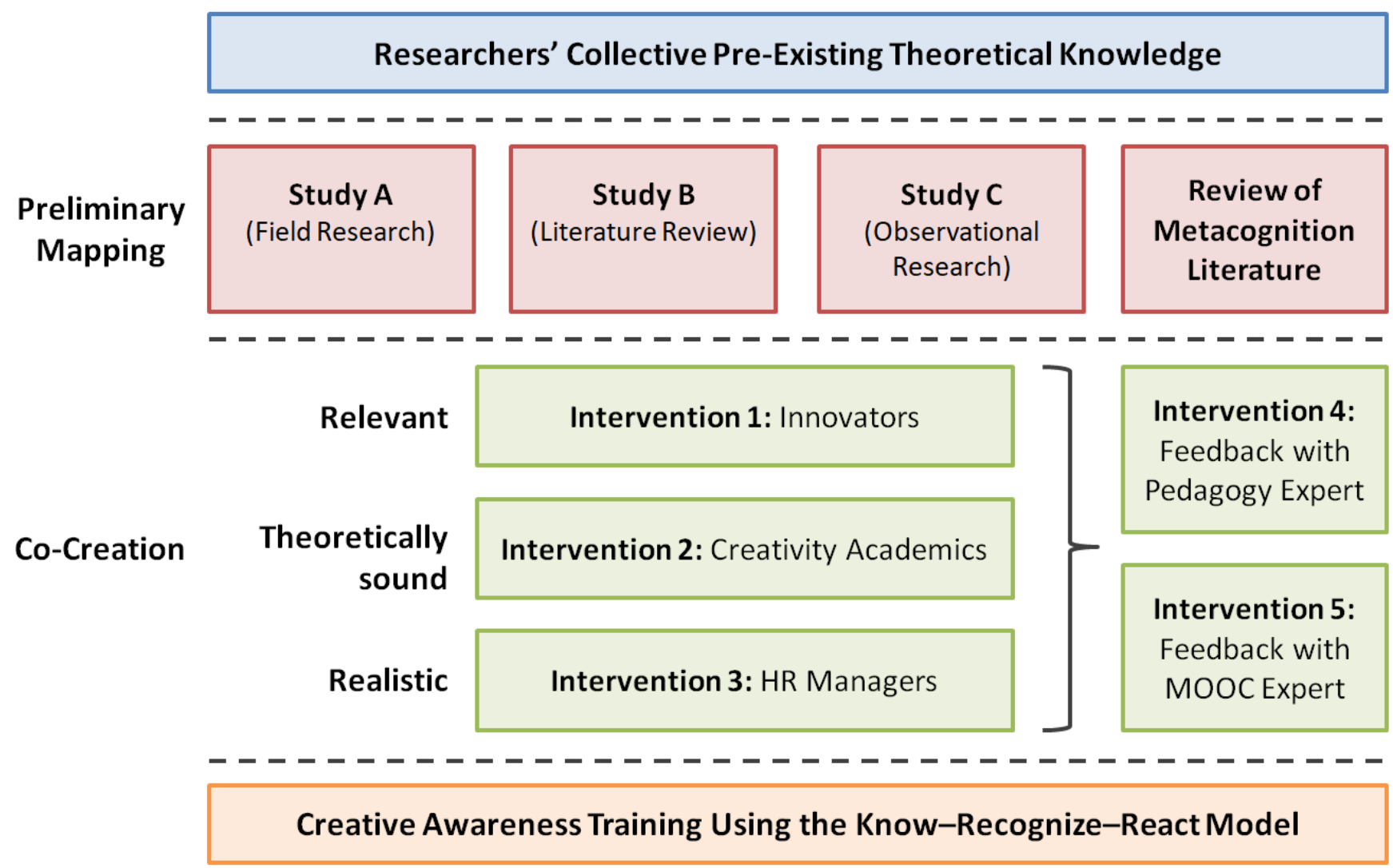

Figure 1. Overall research process leading to the development of training program. The "co-creation" portion of the process delimits the current study. 


\section{Realistic Creativity Training for Innovation Practitioners: Know-Recognize-React} Dagny Valgeirsdottir and Balder Onarheim

gical approach and present the findings from the transdisciplinary process. Finally, we discuss the findings, outline the conclusions, and highlight the practical implications and contribution to the fields of creativity and innovation management.

\section{Theoretical Background}

Theoretical approaches towards creativity may be considered in terms of which form of creativity they emphasize, taking departure from the four Ps of creativity (Rhodes, 1961) which list the creative person, process, product, and press (more recently, persuasion [Simonton, 1990] and potential [Runco, 2003] have been added). In our studies of creativity training, the main focus is on two of the original Ps, namely the creative person and the creative process.

Further forming the theoretical background of our research are two out of the nine major theories of creativity, as categorized in The Cambridge Handbook of Creativity (Kozbelt et al., 2010). Both categories our research aligns with belong to the psychological standpoint of creativity research (e.g., Guilford, 1950; Mednick, 1962). First, we shall mention the psychometric category that is formed in part by representative theories built on the work of Guilford (e.g., 1968) and Wallach and Kogan (e.g., 1965). Within this category, the major focus is on the creative person and the argument that creativity can be differentiated from other constructs such as IQ and can be measured reliably through psychometric tests (Kozbelt et al., 2010) such as the alternate uses test (Christensen et al., 1960; Guilford, 1968) and instances task (Wallach \& Kogan, 1965). The focus of these tests is divergent thinking, which is the cognitive process of generating multiple ideas to a given task (Guilford, 1959). It is the cognitive process that is argued to be trainable and therefore emphasized in many creativity training programs as well as serving as the most common construct of measure (see e.g., Valgeirsdottir \& Onarheim, in press). Divergent thinking is usually accompanied by another cognitive process, convergent thinking (Guilford, 1959), and as pointed out by Onarheim and Friis-Olivarius (2013), these two processes each relate directly to two key features of the standard definition of creativity (Stein, 1953; Runco \& Jaeger, 2012): novel (divergent) and appropriate (convergent). The second category of our work falls under cognitive theories of creativity, which relate to Guilford's "Traits of Creativity" (1959) and the "Associative Basis of the Creative Process" (Mednick, 1962). The cognitive category primarily focuses on the creative person and process, and the primary assertion is that ideational processes are fundamental to the creative person and their subsequent accomplishments in a creative process (Kozbelt et al., 2010). Metacognitive processes are furthermore one of the key concepts within this category, which we will examine in the next section.

\section{Metacognition and creative awareness}

Creative awareness is, as previously stated, a skill that is closely related to metacognition from psychology literature, which refers to "thinking about one's own thinking” (Dunlosky \& Metcalfe, 2008; Flavell, 1979). Metacognition is a cognitive system that helps direct the way individuals solve their tasks through sub-consciously overviewing cognitive functions. There are three facets to metacognition: metacognitive knowledge, metacognitive monitoring, and metacognitive control (Dunlosky \& Metcalfe, 2008). Metacognitive knowledge is knowledge about a given type of cognition (e.g., learning, memory, reasoning, and creativity). Metacognitive monitoring happens when one assesses the current state of cognitive activity (e.g., assessing whether they would be more successful in solving the task at hand using other cognitive strategies). Metacognitive control follows if the individual, as a result of their metacognitive monitoring subsequently regulates some parts of their cognitive activities. Metacognition is a broad concept, encompassing all types of cognitive activities, and we see metacognition as being an umbrella concept under which creative awareness fits. Creative awareness is limited to creativity-related acts, and not other distinct cognitive processes. It materializes when individuals are aware of the different stages of their creative process, as well as the underlying cognitive processes that could influence their creative abilities. This awareness is also beneficial for advancing the team process (Valgeirsdottir et al., 2016; Valgeirsdottir \& Onarheim, 2016). We define creative awareness as follows:

\footnotetext{
"Creative awareness is a cognitive creativity ability that individuals in a team use to facilitate a creative process. This creative process can be either their own, their team's or when designing a process for other participants. The individual applies their knowledge of cognitive processes and creativity concepts, by being aware of the potential influence of said processes and concepts on the creative process." (Valgeirsdottir \& Onarheim, 2016)
}

Creative awareness is an ability that allows an individual to become conscious of the cognitive processes involved in a creative process, such as divergent and 


\section{Realistic Creativity Training for Innovation Practitioners: Know-Recognize-React} Dagny Valgeirsdottir and Balder Onarheim

convergent thinking (Guilford, 1959), associational processes (Mednick, 1962), and the five key concepts of creativity (Onarheim \& Friis-Olivarius, 2013), which in addition to "remote associations" include cognitive inhibition, priming, fixation, and incubation. This ability requires both knowledge of said processes and self-observation and regulation in line with metacognition in order to understand one's own and other's creative processes. The deployment of the creative awareness ability may thus enable the individual to enhance their creative potential. It also enables them to be more deliberate when getting involved in a creative process to avoid possible pitfalls and to generate required conditions through regulation and subsequent reactions to advance the creative process. Therefore, it seems relevant to teach participants about cognitive processes in creativity training and employ metacognitive methods to enable creative awareness.

\section{Creativity training}

Creativity training programs are not a new phenomenon; the first known program dates back to 1953 (Osborn). Several meta-analyses comparing results of individual studies on training efforts have been published (e.g., Rose \& Lin, 1984; Scott et al., 2004; Ma, 2006), with the study by Scott, Leritz, and Mumford (2004) being the most prominent. Their review of 70 programs revealed that many different approaches have been deployed with the purpose of enhancing creativity, but the most important result of the meta-analysis was that creativity training does work (Scott et al., 2004). However, due to the lack of definitional clarity of "creativity training programs" we have proposed the following definition:

\section{"A creativity training program is a pre-defined and structured program consisting of one or mul- tiple sessions, with the main purpose of increasing the creativity of one or multiple participants." (Val- geirsdottir \& Onarheim, in press)}

The review by Scott and colleagues (2004) provides an overview of previous training efforts and the different aspects of creativity they focused on (e.g., problem solving, associational mechanisms, and divergent thinking). Earlier, Bull and colleagues (1991) identified four common approaches to creativity training: cognitive, personality, motivational, and social interaction approaches. More recently, we reviewed the identified categories with a focus on the methods of delivery: traditional, computer-based, physical, and cognitive (Valgeirsdottir \& Onarheim, in press).
Divergent thinking is the most common skill in focus in creativity training programs (Fasko, 2001), however, focus has also been put on problem-solving abilities. Problem solving is the foundation of many established creativity training programs such as the Creative Problem Solving program (Parnes \& Noller, 1972). Scott and colleagues (2004) proposed an optimal format for the delivery of creativity training, which consists of four key aspects:

1. Training should be built on teaching about the cognitive theories of creativity

2. The theoretical teaching should be a substantial part of the overall length of the training, and it should be detailed in describing the cognitive and associative skills underlying creative effort.

3. After learning about the attributes underlying creative effort, the participants should put them to use while solving a real-world case in a co-operative learning environment.

4. The presentation of the case material should be complemented by diverse exercises and tools to provide participants with practice in using relevant strategies and heuristics while solving the real-world case.

\section{Research Design}

In this article, we will describe our transdisciplinary study. A transdisciplinary approach "includes interdisciplinary but goes a step further and transcends the margin of science" (Rasmussen et al., 2010) where nonscientific stakeholders are included in the production of knowledge (Lengwiler, 2006). Our study had the aims of investigating which creativity skills are important for raising creative awareness and developing a training program for innovators through using the method of co-creation (Sanders \& Stappers, 2008). The reason for selecting a co-creation approach was to ensure that the program is relevant, theoretically sound, and realistic for a real-world context.

\section{Co-creation process}

In co-creation, there are two approaches that should be taken into consideration. First is the overarching co-creation process the researchers plan with a pre-defined purpose as well as preliminary mapping of pre-existing knowledge (Visser et al., 2005). In this case, the preliminary mapping (Figure 1) consisted of two years of prior research efforts, which included Studies A, B, and C 


\section{Realistic Creativity Training for Innovation Practitioners: Know-Recognize-React}

Dagny Valgeirsdottir and Balder Onarheim

(Valgeirsdottir et al., 2016; Valgeirsdottir \& Onarheim, in press; 2016). Second are interventions strategically placed at different intervals within the overarching process. The interventions are deployed with the aim of reaching the pre-defined purpose of the co-creation process utilizing pre-planned methods and carefully selected participants (Visser et al., 2005). Interventions can take the form of feedback sessions, expert interviews, and generative sessions where scientific or nonscientific participants are included in knowledge production and material analysis (Rasmussen et al., 2010). Data collection can be in the form of researcher notes and material generated by participants during sessions. In co-creation, researchers are facilitators and encourage participants to express themselves (Sanders \& Stappers, 2008). The interventions deployed here were three generative sessions designed to explore the tacit and latent knowledge of the participants (Visser et al., 2005) through specific exercises and instructions. Further interventions were two feedback sessions with educational scientists who utilized their knowledge to validate pedagogical aspects of the training program to ensure optimization when we further concretized it.

\section{Descriptive aspects of co-creation interventions}

The optimal number of participants in generative sessions is between four and six (Visser et al., 2005). Intervention 1 included six participants whose knowledge would ensure a relevant program for innovators. The participants shared their knowledge on the topic, and facilitators probed into their tacit knowledge of what would be of most value to them to include in the training. The participants all had more than five years of pro-

Table 1. Occupations and industries represented by participants in Intervention 1

\begin{tabular}{ll}
\hline Occupation & Industry \\
\hline Senior R\&D user research lead & Healthcare \\
\hline Senior UX researcher & Digital industrial \\
\hline Senior UX researcher & Automotive \\
\hline $\begin{array}{l}\text { Chief principal innovation } \\
\text { manager, R\&D }\end{array}$ & Medical equipment \\
\hline $\begin{array}{l}\text { Industrial designer and } \\
\text { entrepreneur }\end{array}$ & Medical equipment \\
\hline $\begin{array}{l}\text { Innovation manager, FE } \\
\text { innovation }\end{array}$ & Medical equipment \\
\hline
\end{tabular}

fessional experience working within the fuzzy front-end of innovation and their positions at the time are listed in Table 1. Their industries are listed as well, although they were not the focus in selecting the participants; the focus was more on the innovation process and the participants' experiences from the fuzzy front-end.

The output from Intervention 1 was used to design parts of Intervention 2. The purpose of doing so was to ensure that the elements included in the program design from Intervention 1 would be theoretically sound. Secondly, a theoretical perspective was gained through facilitated probing into their expert knowledge on the topic. Participants in Intervention 2 were four academic employees at three Danish universities. Each of them had expertise in creativity research and teaching responsibilities in creativity related courses, each with minimum seven years of academic experience.

The outputs from Interventions 1 and 2 were synthesized (as described below) and used to design parts of Intervention 3, which had the purpose of gaining insights from four practitioners with experience in human resource (HR) management (Table 2) in major Danish companies. This intervention was done to ensure a realistic program for real-world contexts in terms of both content and format of the training program, such as the length and time distribution.

The output from the first three interventions was, again, synthesized and presented to two academic scientists in Interventions 4 and 5, where an expert in pedagogy and education was consulted as well as an expert in massive online open courses (MOOCs). The purpose of the two last interventions was to present the experts with the first draft of the training program and obtain feedback regarding pedagogical aspects and program design. These sessions were validating in nature and contributed to the robustness of the final version of the training program.

Table 2. Occupations and industries represented by participants in Intervention 3

\begin{tabular}{ll}
\hline Occupation & Industry \\
\hline HR development consultant & HR consultancy \\
\hline HR business partner & Banking \\
\hline HR development consultant & Banking \\
\hline HR business partner & Engineering \\
\hline
\end{tabular}




\section{Realistic Creativity Training for Innovation Practitioners: Know-Recognize-React}

\section{Dagny Valgeirsdottir and Balder Onarheim}

\section{Data analysis}

Below is a description of the process of analysis for the generative sessions (Interventions 1, 2, and 3). The feedback and validation sessions (Interventions 4 and 5) will be addressed in the section on Findings.

Data collected during generative sessions was in the form of researcher notes, video recordings, and other generated material such as notes written by participants, templates filled out, etc. The data was analyzed in the manner of analyzing case studies (Eisenhardt, 1989), where each session was treated as a case. The analysis was done systematically throughout the process where data from each intervention underwent four levels of analysis, or "filters", as shown in Figure 2, and described below:

- Filter 1: The analysis began during each session when participants filtered their own material, for example by summarizing and prioritizing outputs into Top 3 lists.

- Filter 2: At the conclusion of each session, the researchers went through generated material and chose which to collect from the session.

- Filter 3: In the days following each session, the researchers reviewed the data, synthesized it further, and organized the results in digital form.

- Filter 4: Following a two-week incubation period, the researchers re-evaluated the data. Finally, all material, including video recordings, was reviewed and analyzed to find input for the next intervention session and input for the program itself.

The collected data from each session mainly consisted of researcher notes and generated material from the first filter, in addition to other material generated through specific templates that were designed to tap into the participants' tacit knowledge. During within-case analysis (Eisenhardt, 1989), the researchers spent extensive time reviewing the data in order to become adequately familiar with it, as recommended in the literature (e.g., Boyatzis, 1998). The incubation period between Filters 3 and 4 allowed the researchers to distance themselves from the material in order to gain a new perspective (Tan et al., 2015) when re-evaluating the data during the final filter. Subsequent cross-case analysis (Eisenhardt, 1989) enabled the researchers to look for similarities and differences in the data.

\section{Findings}

Notes made by the researchers during the generative sessions mainly focused on three areas of interest. First was novelty: the researchers looked for indications and inspiration for aspects of training that were not known to exist in other training programs. For example, in Intervention 1, participants came up with an idea to send participants on a forest trip. The purpose was to take them out of a familiar context and conduct training in a novel place. Although this idea was not literally implemented in the program design, it highlighted the importance of the training environment. Second was noting down instances where participants voiced observations of each other's work. For example, in Intervention 2, the academics were asked to design a training program, and although each of them came up with different outputs, the interactions that followed were especially interesting, particularly when similarities and differences between their versions were discussed. Third were notes regarding material that was generated through specific exercises that had the purpose of prob-

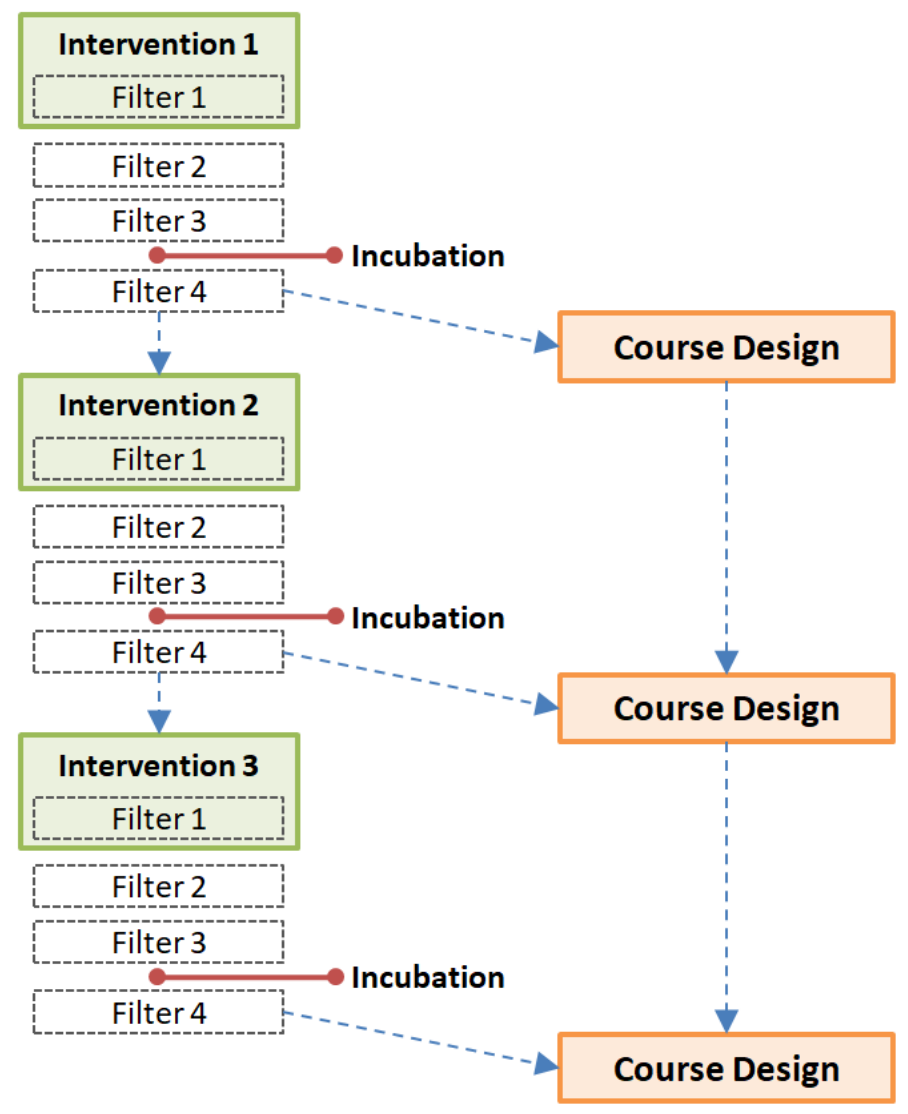

Figure 2. Process of analysis 


\section{Realistic Creativity Training for Innovation Practitioners: Know-Recognize-React}

Dagny Valgeirsdottir and Balder Onarheim

ing the participants' tacit knowledge. For example, in Intervention 1, it was revealed that trust was an important factor for behavioural change, and the participants appeared to focus more on behaviour than cognitive processes, even though the latter were the foundation of the session.

\section{Generated material}

Through the research design, we identified which creativity-related processes were deemed important by innovators. Furthermore, we compared those results to creativity-related processes identified in the creativity literature as well as those deemed as important by the creativity academics in Intervention 2. Tables 3 and 4 provide overviews of the resulting lists.

The two tables reveal notable differences that highlight the importance of including different stakeholders in the process. During Intervention 1, the focus was, as previously stated, more on behavioural aspects the innovators associated with creative work, whereas the academics in Intervention 2 focused more on the cog- nitive processes associated with creativity. The HR managers in Intervention 3 focused less on the content, but more on the format for training, the formalities, and the types of individuals who should be trained.

\section{Feedback and validation sessions}

Once the data from the three generative sessions had been analyzed, a first draft of the training program was developed. To further strengthen the program's robustness (Rasmussen et al., 2010), the draft was presented to academics with expertise in educational development and pedagogy. Their feedback was taken into consideration when developing the second draft of the training program. After an iterative process of program development, where both the output from the co-creation process and the output of an extensive literature research were considered, we finally designed the first edition of the Creative Awareness Training program, which focuses on enhancing creative awareness while emphasizing the creativity-related processes identified in the generative sessions using metacognitive teaching methods.

Table 3. Prioritized list of creativity-related processes from Intervention 1

\begin{tabular}{clll}
\hline Participant & First Priority & Second Priority & Third Priority \\
\hline 1 & Cross pollination & Zooming & Openness \\
\hline 2 & Not afraid & Curious & Communication \\
\hline 3 & Curiosity & Ability to express & Reflection on own and others' behaviour \\
\hline 4 & Motivation/curiosity & Trust & Scope \\
\hline 5 & Facilitation & Framing & Pattern recognition \\
\hline 6 & Suspension of disbelief & Encouraging & Communication approaches \\
\hline
\end{tabular}

Table 4. Prioritized list of creativity-related processes from Intervention 2

\begin{tabular}{clll}
\hline Participant & First Priority & Second Priority & Third Priority \\
\hline 1 & Self-efficacy & Association skills & Persistence \\
\hline 2 & $\begin{array}{l}\text { Domain-specific } \\
\text { expertise }\end{array}$ & Openness & Persistence \\
\hline 3 & Cognitive fluency & Association skills & Self-motivation \\
\hline
\end{tabular}




\section{Realistic Creativity Training for Innovation Practitioners: Know-Recognize-React} Dagny Valgeirsdottir and Balder Onarheim

\section{Creative Awareness Training: Know-Recognize-React}

The Creative Awareness Training program we have developed is a result of several previous research efforts, as described in Figure 1 and in the Introduction. Here, we will discuss the findings from our transdisciplinary study that contributed to the program design through co-creation. The training program focuses on enabling the active use of the metacognitive skill we have termed creative awareness, thus we named the program Creative Awareness Training (Valgeirsdottir \& Onarheim, 2016). The three generative interventions resulted in prioritized lists of creativity-related processes deemed important by innovators (Intervention 1) and creativity academics (Intervention 2). After the data had been analyzed, the findings were compared to the literature to validate its importance.

When viewing the creativity-related processes, it became apparent that they could be categorized into four levels: cognitive processes, personality traits, social skills, and management skills. As a result, the overall conceptualization of the training program consists of four modules, each allocated to one of the levels. The module we have now developed is the first one, which focuses mainly on cognitive creativity processes. The second module will focus on personality traits that can be thought of as supporting the core cognitive creativity, thereby propelling the individual creativity. Modules three and four will take the social dimensions into account by focusing on team dynamics and the collective dimensions of creativity. We argue that individual creativity provides the building blocks on which organizational creativity and innovation are built, thus they are the focus of the first module which we have now developed. The resulting description of findings will therefore focus on the cognitive module of our Creative Awareness Training.

The processes related to cognitive creativity were allocated into six sessions, each focusing on training specific skills to manage those processes. The training is based on a model we have termed Know-Recognize-React. The model was formulated after an extensive literature review of the metacognition literature (Dunlosky \& Metcalfe, 2008; Flavell, 1979; Nelson \& Narens, 1990) and metacognitive approaches to teaching (Hargrove \& Nietfeld, 2014; Mevarech \& Kramarski, 1997; Schraw, 1998; Schraw et al., 2005). As introduced above, metacognition has three facets: metacognitive knowledge, metacognitive monitoring, and metacognitive control (Dunlosky \& Metcalfe, 2008). These were the inspira- tion for the Know-Recognize-React model we implemented into our Creative Awareness Training program. We aspire to teach our participants about the creativityrelated concepts and processes they should Know (derived from metacognitive knowledge) followed by specifically designed exercises for the participants to be able to Recognize (derived from metacognitive monitoring) those processes, and finally introduce strategies and tools in order for the participants to be equipped to React (derived from metacognitive control) appropriately in situations where they encounter said creativityrelated processes. An example is where we teach participants about divergent and convergent thinking (Guilford, 1959) because they provide the cognitive basis of creativity in addition to the associative basis (Mednick, 1962). Participants learn about the different processes (Know), go through specific exercises to experience first-hand how the different processes work (Recognize), followed by reflecting discussions where they are equipped with examples of how these might materialize in the real world as well as knowledge about how to strategically work most efficiently when deploying the different cognitive activities (React). Moreover, participants are taught about how the planned process consists of sequential series of diverging and converging and subsequently the same Know-Recognize-React model is applied.

In addition to the creativity-related processes to be emphasized in the training, as identified in Interventions 1 and 2, the format of the program was designed to fit the output from Intervention 3, during which the HR managers provided their knowledge. Thus, the execution of the program was condensed (in opposition to distributed over time) and limited to two full working days including preparation time; this timeframe was a direct result of Intervention 3. The curriculum consists of learning material, which should be consumed before initiating the program but within the two-day constraint, as indicated by the results of Intervention 3. The HR managers also indicated that it would be beneficial to direct the training with new employees. In addition to the pre-consumed learning material, made as a result of feedback from Intervention 5, the program consists of specifically designed exercises and training material, which we developed while taking into consideration pedagogical aspects deriving from metacognitive teaching methods (Schraw, 1998). Those exercises are completed throughout the six sessions with each exercise focusing on different cognitive creativity processes that were deemed important to train through the transdisciplinary study (Interventions 1 and 2). The program design furthermore corresponds to what Scott 


\section{Realistic Creativity Training for Innovation Practitioners: Know-Recognize-React} Dagny Valgeirsdottir and Balder Onarheim

and colleagues (2004) specified as the optimal format of delivering creativity training. We do build the training on a concrete theoretical foundation by teaching participants about the cognitive basis of creativity. Furthermore, the theoretical part is a substantial aspect of the training, first within the pre-consumed learning material and second within the actual training, where theory is taught followed by the specifically designed exercises, which do to some extent rely on real-world cases. The training takes place almost entirely within a co-operative learning environment, as validated in Intervention 4 and also recommended to activate metacognitive processing (Mevarech \& Kramarski, 1997). Finally, all of the material is complemented with a diverse library of exercises and tools that participants both complete during the training and can subsequently utilize to maintain their training for a more long-term result.

We theorize that, through this cross-fertilization of metacognition into both the program material as well as the pedagogical approach, the creative awareness of individuals will be enhanced and they will be able to perform their creative work more efficiently and with more creative self-efficacy. Future research efforts include a controlled experiment following the three criteria for studying the effectiveness of creativity training programs (Valgeirsdottir \& Onarheim, in press), as well as the development of modules two, three, and four of the Creative Awareness Training. Finally, our aim is to test the long-term effects of the training.

\section{Conclusion}

In this article, we have presented a novel research approach to develop relevant, rigorous, and realistic training. Furthermore, we have presented the resulting first module of our more extensive Creative Awareness Training program. Through our study, we hope to contribute to the fields of creativity and innovation research with these two aspects: an inclusive research approach resulting in the development of our program aimed at enhancing the creativity of innovators. Creativity is an important problem-solving skill at any level of the innovation process, and through our Creative Awareness Training innovators will be able to train their creativity and raise their creative awareness level. Creative awareness is an important metacognitive skill, being a crucial mechanism to enhance all stages of the creative process. If an innovator becomes able to "Know, Recognize, and React" to situations dictated by creativity-related processes, they will be able to understand what works and what does not work for advancing the creative process. In turn, that enables them to become more strategic about which actions are appropriate and at what time they are most usefully deployed. Thus, they are able to make use of strategies, methods, and tools not just as an automatic procedure but as a highly conscious and purposeful one. In time, we believe this will enable innovators to become more efficient when working within innovation processes as a result of having mastered recognizing elements that can either potentially hinder or advance their processes and subsequently reacting accordingly.

\section{Acknowledgements}

An earlier version of this article was presented at the ISPIM Innovation Forum in Toronto, Canada, March 19-22, 2017. ISPIM (ispim-innovation.com) - the International Society for Professional Innovation Management - is a network of researchers, industrialists, consultants, and public bodies who share an interest in innovation management.

\section{About the Authors}

Dagny Valgeirsdottir is a $\mathrm{PhD}$ researcher and is part of the Innovation, Design and Entrepreneurship research group in the Department of Management Engineering at the Technical University of Denmark. Her research focuses on developing ways to enhance individual creativity by optimizing creativity training through the application of metacognitive approaches. She is the author of numerous articles on the topic and is currently working on finalizing her dissertation. Dagny furthermore contributes to the Copenhagen Institute of NeuroCreativity, which is an institute devoted to enhancing creativity of individuals and teams applying principles from neuroscience.

Balder Onarheim is Associate Professor in Creativity and is part of the Innovation, Design and Entrepreneurship research group in the Department of Management Engineering at the Technical University of Denmark. His expertise lies within a neurobiological understanding of creativity and methods to use this understanding to improve individuals' capabilities in creative problem solving. Balder is moreover the founder of the Copenhagen Institute of NeuroCreativity and the CEO at PlatoScience, which is making a neurostimulator to enhance performance in knowledge work. 


\section{Realistic Creativity Training for Innovation Practitioners: Know-Recognize-React}

Dagny Valgeirsdottir and Balder Onarheim

\section{References}

Amabile, T. M. 1996. Creativity and Innovation in Organizations. Harvard Business School Background Note, 396-239. Boston, MA: Harvard Business School.

Boyatzis, R. E. 1998. Transforming Qualitative Information: Thematic Analysis and Code Development. London: Sage Publications.

Bull, K. S., Montgomery, D., \& Baloche, L. 1995. Teaching Creativity at the College Level: A Synthesis of Curricular Components Perceived as Important by Instructors. Creativity Research Journal, 8(1): 83-89. http://dx.doi.org/10.1207/s15326934crj0801_7

Christensen, P. R., Guilford, J. P., Merrifield, P. R., Wilson, R. C. 1960. Alternate Uses, Form A: Manual of Administration, Scoring and Interpretation. Beverley Hills, CA: Sheridan Supply Co.

Christiaans, H. H. C. M. 1992. Creativity in Design: The Role of Domain Knowledge in Designing. Delft, The Netherlands: Delft University of Technology.

Dorst, K., \& Cross, N. 2001. Creativity in the Design Process: CoEvolution of Problem-Solution. Design Studies, 22(5): 425-437. https://doi.org/10.1016/S0142-694X(01)00009-6

Dunlosky, J., \& Metcalfe, J. 2008. Metacognition. London: Sage Publications.

Eisenhardt, K. M. 1989. Building Theories from Case Study Research. Academy of Management Review, 14(4): 532-550. http://www.jstor.org/stable/258557

Fasko, D. 2001. Education and Creativity. Creativity Research Journal, 13(3-4): 317-327. http://dx.doi.org/10.1207/S15326934CRJ1334_09

Flavell, J. H. 1979. Metacognition and Cognitive Monitoring: A New Area of Cognitive-Developmental Inquiry. American Psychologist, 34(10): 906-911. http://dx.doi.org//10.1037/0003-066X.34.10.906

Guilford, J. P. 1950. Creativity. American Psychologist, 5(9): 444-454. http://dx.doi.org/10.1037/h0063487

Guilford, J. P. 1968. Intelligence, Creativity, and their Educational Implications. San Diego, CA: RR Knapp.

Guilford, J. P. 1959. Traits of Creativity. In H. H. Anderson (Ed.), Creativity and Its Cultivation: 141-161. New York: Harper and Row.

Hargrove, R. A., \& Nietfeld, J. L. 2014. The Impact of Metacognitive Instruction on Creative Problem Solving. The Journal of Experimental Education, 83(3): 291-318.

http://dx.doi.org/10.1080/00220973.2013.876604

Koen, P. A. et al. 2002. Fuzzy Front End: Effective Methods, Tools, and Techniques. In P. Belliveau, Griffin, A., \& Somermeyer, S. (Eds.), The PDMA Toolbook for New Product Development: 5-35. Hoboken, NJ: Wiley.

Kozbelt, A., Beghetto, R. A., \& Runco, M. A. 2010. Theories of Creativity. In J. C. Kaufman \& R. J. Sternberg, (Eds.), The Cambridge Handbook of Creativity: 20-47. Cambridge, MA: Cambridge University Press.

Lengwiler, M. 2006. Between Charisma and Heuristics: Four Styles of Interdisciplinarity. Science and Public Policy, 33(6): 423-434. https://doi.org/10.3152/147154306781778821
Ma, H.-H. 2006. A Synthetic Analysis of the Effectiveness of Single Components and Packages in Creativity Training Programs. Creativity Research Journal, 18(4): 37-41.

Mednick, S. 1962. The Associative Basis of the Creative Process. Psychological Review, 69(3): 220-232. http://dx.doi.org/10.1037/h0048850

Mevarech, Z. R., \& Kramarski, B. 1997. Improve: A Multidimensional Method for Teaching Mathematics. American Educational Research Journal, 34(2): 365-394. https://doi.org/10.3102/00028312034002365

Nelson, T. O., \& Narens, L. 1990. Metamemory: A Theoretical Framework and New Findings. The Psychology of Learning and Motivation, 26: 125-141.

https://doi.org/10.1016/S0079-7421(08)60053-5

Onarheim, B., \& Friis-Olivarius, M. 2013. Applying the Neuroscience of Creativity to Creativity Training. Frontiers in Human Neuroscience, 7: 656.

https://doi.org/10.3389/fnhum.2013.00656

Osborn, A. F. 1953. Applied Imagination: Principles and Procedures for Creative Thinking. Oxford: Schribner.

Parnes, S. J., \& Noller, R. B. 1972. Applied Creativity: The Creative Studies Project: Part II - Results of the Two-Year Program. The Journal of Creative Behavior, 6(3): 164-186. http://dx.doi.org/10.1002/j.2162-6057.1972.tb00927.x

Rasmussen, B., Andersen, P. D., \& Borch, K. 2010. Managing Transdisciplinarity in Strategic Foresight. Creativity and Innovation Management, 19(1): 37-46. http://dx.doi.org/10.1111/j.1467-8691.2009.00534.x

Rhodes, M. 1961. An Analysis of Creativity. The Phi Delta Kappan, 42(7): 305-310.

http://www.jstor.org/stable/20342603

Rose, L. H., \& Lin, H. 1984. A Meta-Analysis of Long-Term Creativity Training Programs. The Journal of Creative Behavior, 18(1): 11-22. http://dx.doi.org/10.1002/j.2162-6057.1984.tb00985.x

Runco, M. A. 2003. Education for Creative Potential. Scandinavian Journal of Educational Research, 47(3): 317-324. http://dx.doi.org/10.1080/00313830308598

Runco, M. A., \& Jaeger, G. J. 2012. The Standard Definition of Creativity. Creativity Research Journal, 24(1): 92-96. http://dx.doi.org/10.1080/10400419.2012.650092

Sanders, E. B.-N., \& Stappers, P. J. 2008. Co-Creation and the New Landscapes of Design. CoDesign, 4(1): 5-18. http://dx.doi.org/10.1080/15710880701875068

Schraw, G. 1998. Promoting General Metacognitive Awareness. Instructional Science, 26(1): 113-125. http://dx.doi.org/10.1023/A:1003044231033

Schraw, G., Brooks, D. W., \& Crippen, K. J. 2005. Using an Interactive, Compensatory Model of Learning to Improve Chemistry Teaching. Journal of Chemical Education, 82(4): 637-640. http://dx.doi.org/10.1021/ed082p637

Scott, G., Leritz, L. E., \& Mumford, M. D. 2004. The Effectiveness of Creativity Training: A Quantitative Review. Creativity Research Journal, 16(4): 361-388.

http://dx.doi.org/10.1080/10400410409534549 


\section{Realistic Creativity Training for Innovation Practitioners: Know-Recognize-React}

Dagny Valgeirsdottir and Balder Onarheim

Simonton, D. K. 1990. History, Chemistry, Psychology, and Genius: An Intellectual Autobiography of Historiometry. In M. Runco \& R. Albert (Eds.), Theories of Creativity: 92-115. Newbury Park, CA: Sage Publications.

Stein, M. I. 1953. Creativity and Culture. The Journal of Psychology, 36(2): 311-322.

http://dx.doi.org/10.1080/00223980.1953.9712897

Tan, T., Zou, H., Chen, C., \& Luo, J. 2015. Mind Wandering and the Incubation Effect in Insight Problem Solving. Creativity Research Journal, 27(4): 375-382.

http://dx.doi.org/10.1080/10400419.2015.1088290

Valgeirsdottir, D., \& Onarheim, B. 2016. Metacognition in Creativity: Process Awareness Used to Facilitate the Creative Process. Paper presented at the 11th Design Thinking Research Symposium. Copenhagen, Denmark.
Valgeirsdottir, D., \& Onarheim, B. In Press. Studying Creativity Training Programs: A Methodological Analysis. Creativity and Innovation Management.

Valgeirsdottir, D., Onarheim, B., \& Li-Ying, J. 2016. Improving Creativity Training: A Study of Designer Skills. In Proceedings of the 14th International Design Conference: 1175-1184. Dubrovnik, Croatia: Design Society.

Visser, F. S., Stappers, P. J., van der Lugt, R., \& Sanders, E. B.-N. 2005. Contextmapping: Experiences from Practice. CoDesign, 1(2): 119-149.

http://dx.doi.org/10.1080/15710880500135987

Wallach, M. A., \& Kogan, N. 1965. Modes of Thinking in Young Children: A Study of the Creativity-Intelligence Distinction. New York: Holt, Rinehart \& Winston.

Citation: Valgiersdottir, D., \& Onarheim, B. 2017. Realistic Creativity Training for Innovation Practitioners: The Know-Recognize-React Model.

Technology Innovation Management Review, 7(6): 5-15. http://timreview.ca/article/1080

(cc) BY

Keywords: creativity, creativity training, creative process, innovation process, front-end innovation, cognitive creativity, creative awareness, metacognition, transdisciplinary, co-creation 